\title{
ITRF96-ED50 Transformasyonu: Radyal esaslı enterpolasyon ve küresel harmonik modelleme
}

\author{
Illke Deniz ${ }^{1+(1)}$, Şenol Hakan Kutoğlu' (i), Rasim Deniz ${ }^{2}$ (i) \\ ${ }^{1}$ Zonguldak Bülent Ecevit Üniversitesi, Mühendislik Fakültesi, Geomatik Mühendisliği Bölümü, Merkez, Zonguldak, Türkiye. \\ 2istanbul Teknik Üniversitesi, Ayazağa Kampüsü, Inşaat Fakültesi, Geomatik Mühendisliği Bölümü, Sarıyer, Istanbul, Türkiye.
}

Öz: Datum transformasyonu; doğrudan, ortak noktaların koordinatları arasındaki geometrik bağıntılar ile veya ortak noktaların koordinat farklarının gridlenmesi veya modellenmesi yoluyla gerçekleştirilir. Bu çalışmada; 2591 ortak nokta verisi kullanıla rak bir grid çerçevesinin elde edilmesi için uzunluğun tersi ağırlıkl enterpolasyon yöntemi ve küresel harmonik fonksiyonlarla modelleme yöntemi uygulanmış ve bu yöntemlerin doğrulukları 25 kontrol noktasıyla belirlenmiştir. Değerlendirmelerden önce verideki trend "Standart Molodensky Transformasyonu” ile büyük ölçüde giderilmiştir. Orijinal verinin uzunluğun tersi ağırlıkl enterpolasyonu ile, 15 'x15' lık, $66 \times 20=1320$ noktalık bir grid çerçevesi üretilmiştir. Bu çerçeve kullanılarak, kontrol noktalarının uzunluğun tersi ağırlıklı enterpolasyon ile hesaplanan datum parametrelerinin doğruluklarl, boylamda $\pm 0.225 \mathrm{~m}$ ve enlemde $\pm 0.189 \mathrm{~m}$ bulunmuştur. Orijinal verinin küresel harmonik fonksiyonlarla modellenmesinin duyarlığı boylamda $\pm 0.035^{\prime \prime}(\sim 0.84 \mathrm{~m})$ ve enlemde $\pm 0.0245^{\prime \prime}(\sim 0.76 \mathrm{~m})$ bulunmuştur. Gridlenmiş veri de, küresel harmonik fonksiyonlarla modellenmiștir. Bu modellemenin duyarlı̆̆l, boylamda $\pm 0.0177 "$ " ( 0.424 m) ve enlemde $\pm 0.0129 "$ $(\sim 0.398$ m) bulunmuştur. Bu model kullanılarak, kontrol noktalarının datum parametreleri hesaplanmıştır. Kontrol noktalarının datum parametrelerinin doğruluğu boylamda, \pm 0.38 m ve enlemde \pm 0.28 m bulunmuştur.

Anahtar Sözcükler: Datum transformasyonu, Radyal esaslı enterpolasyon, Küresel harmonik fonksiyonlar

\section{ITRF96-ED50 Conversion: Radial basis interpolation and modelling with spherical harmonics}

Abstract: Datum transformation is carried out directly by geometric relations between the coordinates of common points or by gridding or modeling the coordinate differences of common points. In this study, to obtain a grid frame using 2591 common point data, the inverse distance weighted interpolation method and spherical harmonic functions modeling method are applied and the accuracies of these methods are determined with 25 control points. Before the evaluations, the trend in the data has been largely eliminated by "Standard Molodensky Transformation". A grid frame of 15'x15' from 66x20 =1320 points is generated by the inverse distance weighted interpolation of the original data. Using this frame, the accuracy of the datum parameters derived from the inverse distance weighted interpolation of the control points is found to be $\pm 0.225 \mathrm{~m}$ for longitude and $\pm 0.189 \mathrm{~m}$ for latitude. The precision of the spherical harmonic functions modeling of the original data is obtained as $\pm 0.035^{\prime \prime}(\sim 0.84 \mathrm{~m})$ for longitude and $\pm 0.0245^{\prime \prime}(\sim 0.76 \mathrm{~m})$ for latitude. Gridded data is also modeled with spherical harmonic functions. The precision of this modeling is found to be $\pm 0.0177 "$ ( $\sim 0.424 \mathrm{~m})$ for longitude and $\pm 0.0129 "$ $(\sim 0.398 \mathrm{~m})$ for latitude. Using this model, the datum parameters of the control points are calculated. The accuracy of the datum parameters of the control points is found to be $\pm 0.38 \mathrm{~m}$ for longitude and $\pm 0.28 \mathrm{~m}$ for latitude.

Keywords: Datum transformation, Radial basis interpolation, Spherical harmonics 


\section{Giriş}

Datum transformasyonu, jeodezinin önemli konularından biridir. Son senelerde, uydu ve uzay tekniklerinin rasyonel kullanılmaya başlanmasıyla, yerin ağırlık merkezinin konumunun ve eksen yönelmelerinin doğrulukları büyük ölçüde artmıştır. Bu sayede, mutlak sisteme yakın yer merkezli koordinat sistemleri ve normal elipsoit tanımlanabilmiştir. Uluslararas1 yersel referans sistemi (International Terrestrial Reference System, ITRS) ve jeodezik referans sistemi 1980'in (Geodetic Reference System 80, GRS80) fiziksel gerçekleşmesi olan Uluslararası yersel referans çerçevesi (International Terrestrial Reference Frame, ITRFxx) datumları “mutlak datum”lar olarak benimsenmiştir.

Uydu ve uzay tekniklerinin ve bu tekniklerle üretilen ürünlerin kullanılması, uluslararası jeodezik referans sistemine entegrasyon gibi nedenlerle, geleneksel yöntemlere dayalı olarak oluşturulan ulusal ve bölgesel referans koordinat sistemleri "bağıl datumlar”’n mutlak datumlarla ilişkilendirilmesi çalışmaları güncel problemler haline gelmiştir.

Türkiye referans koordinat sistemi; 2005 yllında yürürlüğe giren Büyük Ölçekli Harita ve Harita Bilgileri Üretim Yönetmeliği'nde (BÖHHBÜY) (HKMO, 2005), 1996 y1lında güncellenen ITRF datumu ITRF96 (ITRS+GRS 80) olarak alınmıştır. Böylece, ITRF96-ED50 datum transformasyonu problemi ortaya çıkmıştır.

Türkiye Ulusal Temel GPS Ağı (TUTGA) 2000 yılında tamamlanmış ve Türkiye Ulusal Sabit GPS Ağı-Aktif (TUSAGAAktif) 2011 yılında devreye girmiştir. Böylece, uydu ve uzay teknolojilerinin uygulama alanı genişletilmiştir.

Datum transformasyonu çalışmaları değerlendirildiğinde, iki datum arasındaki transformasyonun doğruluğunun genel olarak; her iki sistemdeki ağların doğruluklarına, uzunluk ve doğrultu bozulmalarına, transformasyonda kullanılan ortak noktaların yoğunluğuna ve dağılımına, transformasyonu yapılan alanın büyüklüğüne, kullanılan transformasyon modeline bağlı olduğu görülmektedir (Çepni \& Deniz, 2005; Eren \& Uzel, 2008). Bu çerçevede, geliştirilen modeller; doğrudan, ortak nokta koordinatları arasındaki geometrik bağıntılara dayanan modeller (geometrik modeller; afin, benzerlik, ortogonal transformasyon modelleri), koordinat farklarının gridlenmesi ve/veya modellenmesi esasına dayanan matematiksel yöntemler (polinomlar, enterpolasyon, kollokasyon, sonlu elemanlar, küresel harmonik fonksiyonlar vb.) olmak üzere iki temel gruba ayrilabilir.

2018 BÖHHBÜY'de, datum transformasyonu standartları; " 200 km²'ye kadarki alanlar için en az 4 ortak nokta ve her 200 $\mathrm{km}^{2}$ için 1 ortak nokta ilave" ve "veri-model uyuşum duyarlı̆̆ $1 \pm 9 \mathrm{~cm}$ " olarak verilmektedir (HKMO, 2018). Bu yönetmeliğe göre yerel ölçekte çok sayıda datum parametreleri seti hesaplanmıştır ve kullanılmaktadır.

Tüm Türkiye için, bütüncül datum transformasyonu parametrelerinin hesaplanması çalışmaları da yapılmıştır. Fırat ve Lenk (2002)'de, 212 adet yüksek dereceli Türkiye Nirengi Ağı noktası alınarak gerçekleştirilen 7 parametreli benzerlik transformasyonunda, transformasyon duyarlı̆̆ $75-100 \mathrm{~cm}$ ve fay bölgelerinde 4-5 m olarak verilmektedir. Aynı veri ile kriging yöntemiyle yapılan $3^{\prime} \times 3^{\prime}$ lık gridlemenin transformasyon duyarllğı $15-30 \mathrm{~cm}$ ve fay bölgelerinde 1.5-2 m olarak verilmektedir. Kutoğlu, Mekik ve Akçın (2003)'te, transformasyon parametrelerinin koordinat hatalarından etkilenmesi araştırmıştır. Kutoğlu ve Ayan (1998)'de, üç boyutlu transformasyonda yükseklik probleminin çözüm yaklaşımları araştırılmıştır. Çepni ve Deniz (2005)’te, bütüncül, sürekliliği olan transformasyonlar için sonlu elemanlar yönteminin kullanılması araştırılmıştır.

CORS-TR Projesi'nde, büyük ölçekli çalışmalarda kullanılacak, bütüncül ulusal hücresel transformasyon parametrelerinin hesaplanması da amaçlanmıştır. Bu çerçevede, TKGM, HGM, TCK, İller Bankası vd. kamu kurumlarının ürettiği 
koordinatların derlenmesi ve 3000 civarında yeni ortak noktanın ölçülmesi planlanmıştır (Eren \& Uzel, 2008). Aktuğ vd. (2011)'de, CORS-TR Projesi çerçevesinde derlenen ve ölçülen 4024 nokta ile minimum eğrilik ve kriging yöntemleri kullanılarak $0.13^{\circ} \mathrm{x} 0.10^{\circ}$ 'lik gridlemeler gerçekleştirilmiştir. Her iki yöntemle de birbirine yakın, boylamda $\pm 0.26 \mathrm{~m}$ ve enlemde \pm 0.27 m'lik transformasyon duyarlığı bulunmuştur.

Çalışmalar ve CORS-TR Projesi'nin sonuçları, daha fazla veri ile yeni yöntemlerin de araştırılması gerektiğini vurgulamaktadır. Çalışmalarda, veri-model uyuşumunun yanında, kontrol noktaları ile modelin doğruluğunun (dış duyarlık) da araştırılması gereği ifade edilmektedir. Bir ulusal datum transformasyonu setinin güvenirliği, farklı yöntemlerle elde edilen sonuçların karşılaştırılmasıyla sağlanmalıdır.

Uygulamada hesaplanan çok sayıda yerel ölçekte datum transformasyon parametreleri setlerinin birleştirilmesi, bu parametreler arasındaki sürekliliğin sağlanması jeodezinin temel görevleri arasındadır.

$\mathrm{Bu}$ çalışmanın amacı; tüm Türkiye için, lokal komşuluk yaklaşımı ile, hücresel transformasyona da uygun, radyal esaslı fonksiyonlarla verinin gridlenmesi ve küresel harmonik fonksiyonlarla modellenmesi, her iki yöntemle sağlanan datum transformasyonunun doğruluğunun kontrol noktaları setiyle kontrolü, sonuçların karşılaştırılarak yöntemlerin kullanılabilirliğinin araştırılmasıdır.

\section{Transformasyon Verisinin Tanımı ve Trend Hesabı}

ITRF96 ile ED50 datumları geometrik olarak incelendiğinde aşağıdaki hususlar söz konusudur.

i-) Farklar ED50'nin düzeltmeleri olarak, yani; fark=ITRF96-ED50 ile tanımlanırsa, iki sistemin büyük eksenleri arasındaki fark $\Delta \mathrm{a}=-251 \mathrm{~m}$ ve $\Delta \mathrm{a} / \mathrm{a}=-39.35$ ppm'lik üç boyutlu ölçek farkı oluşturur. Basıklık farkı $\Delta$ f ise, enleme bağlı bir ölçek değişimi verir. Buna göre iki elipsoit benzer değildir.

ii-) ED50'nin orijini ITRF96'ya göre, $\lambda \cong 228.5^{\circ}$ doğu ve Türkiye'ye göre (ortalama boylam $36^{\circ}$ için) doğuya doğru $192.5^{\circ}$ de, yani dönme eksenine göre Türkiye'nin yaklaşık arkasına gelmektedir. ED50 elipsoidi, ITRF96 elipsoidal normali doğrultusunda yaklaşık $40 \mathrm{~m}$ aşağıdadır. Bunun sonucu, yaklaşık -6 - -7 ppm’lik bir indirgeme söz konusudur.

iii-) Ekvator düzleminde koordinat eksenlerinin oluşturduğu bölgelere göre, küçük alanlar örneğin Türkiye ve hatta Avrupa tek bir bölgede kalır. Bu durum, GPS alıcısına göre uyduların bir bölgede dar bir alanda birikmelerine benzerdir ve geometri bozukluğu oluşturur. Bunun sonucu olarak, küçük alanlarda ITRF96 ile ED50 arasındaki üç boyutlu transformasyonlar yeterli doğruluğu sağlayamaz. Ayrıca, transformasyon parametreleri arasında yüksek matematiksel korelasyonlar oluşur ve parametre değerleri birbirine bulaşır (Leick, 2004). Bu durum özellikle dönme ile ölçek parametreleri arasında oluşur. ED50'nin ölçek bozulmaları -6 - -7 ppm ölçeği de dikkate alınarak değerlendirilmeli ve ölçek parametresinin güvenirliği buna göre irdelenmelidir. Ancak, yer üzerinde homojen dağılmış uydu ve uzay istasyonları ağlarının (kuzey ve güney yarım kürede 8 bölge ile güçlü geometri) üç boyutlu datum transformasyonları en yüksek duyarlıkları sağlar.

iv-) ITRF96 mutlak datum olarak alındığında, ED50’nin datum parametreleri $\Delta \mathrm{a}$; elipsoitlerin büyük eksenleri fark1, $\Delta$ f; elipsoitlerin basıklıkları farkı, $\Delta \mathrm{X}, \Delta \mathrm{Y}, \Delta \mathrm{Z}$; öteleme parametreleri, $\varepsilon_{\mathrm{X}}, \varepsilon_{\mathrm{Y}}, \varepsilon_{\mathrm{Z}}$; dönüklük parametreleri, m; ölçek parametresi olacaktır. Eğer bu parametreler bilinirse, ED50 boylamının düzeltmeleri $\Delta \lambda$ ve enleminin düzeltmeleri $\Delta \phi$ ve yükseklik düzeltmeleri $\Delta \mathrm{h}$ hesaplanabilir. Bu düzeltmeler sadece geometrik bağıntılarla hesaplanabilirler. Bunlar, model hatalarından, ağlardaki bozulmalardan, kabuk hareketleri vb. bozucu etkilerden bağımsızdırlar ve Türkiye için ortalama, $\Delta \lambda \cong-1,6^{\prime \prime}$ ve $\Delta \phi \cong-$ 
3,5" civarındadırlar. Bu farklar, ED50 koordinatlarının "trend"ini oluşturur. ED50 için $\Delta \mathrm{a}, \Delta \mathrm{f}$ parametreleri kesin olarak bilinmektedir. Öteleme parametreleri $\Delta \mathrm{X}, \Delta \mathrm{Y}, \Delta \mathrm{Z}$ birçok çalışmada hesaplanmıştır. Eğer;

fark $=\Delta_{\text {fark }}+d$ fark $=\operatorname{ITRF} 96-E D 50$

olarak tanımlanırsa,

$d$ fark $=\operatorname{ITRF} 96-\left(E D 50+\Delta_{\text {fark }}\right)$

ile, ED50 koordinatlarındaki trendlerin büyük bir kısmı giderilebilir. Burada; $\Delta_{\text {fark }}$, trend değeridir ve Molodensky Transformasyon Formülleri ile hesaplanabilir (DMA, 1988; IHO, 2008; NGA, 2014). Her nokta için elipsoitlerin ölçek farklarından ve büyük ölçüde ötelemeden arınmış $d$ fark değerleri elde edilebilir. Datum transformasyonunda, bu değerler enterpole edilebilir ve modellenebilir. Çünkü her nokta için $\Delta_{f a r k}$ değerleri tek ve değişmezdir. Bu değerlendirme stratejisi, FINELTRA (affine transformation by infinite elements), swisstopo, CHENyx06 gibi birçok datum transformasyonunda temel strateji olarak kullanılmaktadır.

\section{Radyal Esaslı Fonksiyonlarla Enterpolasyon}

Koordinat farklarının enterpolasyonu yoluyla bir grid ağının elde edilmesi ve bu grid ağından yine enterpolasyon ile transformasyon izlenen yollardan biridir. Matematikteki enterpolasyon yöntemlerine ilave olarak, bilgisayar grafik ve coğrafi bilgi sistemlerinin de gereksinimleri sonucu, özellikle mekansal enterpolasyon konusunda çok sayıda yöntem geliştirilmiştir. Burada, veriye en uygun enterpolasyon yönteminin seçimi önem kazanmaktadır.

Farklı derecelerde, farklı zamanlarda gerçekleşmiş, kabuk hareketleri, zemin hareketleri, modelleme, bozulma vb. etkileri içeren dağınık koordinat farkları için en uygun enterpolasyon yöntemlerinden biri olarak, Anjyo, Lewis ve Pighin (2014)’te radyal esaslı foksiyonlarla enterpolasyon, Mitas ve Mitasova (1999)'da “lokal komşuluk yaklaşımı ile enterpolasyon” ve URL-1'de “deterministik enterpolasyon” adları ile de ifade edilen "uzunluğun tersi ağırlıklı enterpolasyon” yönteminin de incelenmesi uygun olacaktır. Yöntem ile gerçekleştirilen çalışmalarda, yöntemin veriyi harmanladığı, düzgünleştirdiği ve çok iyi enterpole ettiği ifade edilmektedir (Anjyo, Lewis ve Pighin, 2014; Mitas \& Mitasova, 1999; URL-1).

Uzunluğun tersi ağırlıklı enterpolasyonun matematik modeli;

$F(r)=\sum_{i=1}^{m} \omega_{i} \cdot z\left(r_{i}\right)=\frac{\sum_{i=1}^{m} z\left(r_{i}\right) /\left|r-r_{i}\right|^{p}}{\sum_{j=1}^{m} 1 /\left|r-r_{j}\right|^{p}}$

olarak verilir (Mitas \& Mitasova, 1999). Burada; $\omega_{i}$ noktanın ağırlık fonksiyonu, $z\left(r_{i}\right)$ noktadaki değer, $r$ konum vektörü, $\left|r-r_{i}\right|^{p}$ den, $p=1$ için iki radial vektörün farkı, yani noktalar arasındaki uzunluk olur. Noktalar arasındaki uzunluk $s$ sınırlandırılarak, enterpole edilecek nokta etrafındaki komşu noktaların seçilmesi sağlanır. Bu $s$ yarıçaplı daire, CORS-TR Projesi'ndeki hücre ifadesi ile eşdeğerdir. Hücre alanı büyütülüp küçültülerek en uygun yarıçap belirlenebilir.

\section{Küresel Harmonik Fonksiyonlarla Modelleme}

Datum farkından kaynaklanan koordinat farkları bütüncül bir yaklaşımla da modellenebilir. Bu yaklaşımda datum transformasyonu modelin parametreleri yoluyla sağlanır. Küresel yüzeyler üzerinde skaler alanların modellenmesinde küresel harmonik fonksiyonlar (KHF) vazgeçilmez araçlardır. Küresel harmonik fonksiyonlarla modelleme, sonuçların 
görselleştirilmesi yoluyla analizinde de önemli bir yoldur.

Boylam ve enlem farkları, meridyen ve paraleller doğrultusunda sistematik bileşenlere sahip olabilir veya bazı bölgelerde sistematik bileşenler daha fazladır. Boylam ve enlem farkları skalar boylam farkı ve skalar enlem farkı alanlarını oluşturur. Ancak, genel olarak her iki alanın da düzgün bir gidiş göstereceği söylenebilir.

Genel olarak, üç boyutlu KHF, bir $R$ eğrilik yarıçaplı küresel yüzeyin dışı ve yukarısı için;

$f(r, \varphi, \lambda)=\sum_{n=0}^{\infty}\left(\frac{R}{r}\right)^{n+1} \sum_{m=0}^{n} P_{n m} \sin (\varphi)\left[A_{n m} \cos (m \lambda)+B_{n m} \sin (m \lambda)\right]$

olarak verilir. Burada; $r$ konum vektörü, $\varphi$ enlem, $\lambda$ boylam, $n$ derece, $m$ mertebe, $P_{n m} \sin (\varphi)$ Legendre fonksiyonu, $A_{n m}$ ve $B_{n m}$ harmonik katsayılardır. Eğer $R / r=1$ alınırsa, iki boyutlu modelleme söz konusudur (Deniz, 2020; Vanicek \& Krakiwski, 1986).

Skaler büyüklüklerin en küçük kareler yöntemiyle modellenmesinde;

$a_{n m}=\left(\frac{R}{r}\right)^{n+1} P_{n m} \sin (\varphi) \cos (m \lambda)$

$b_{n m}=\left(\frac{R}{r}\right)^{n+1} P_{n m} \sin (\varphi) \sin (m \lambda)$

alınarak, belirlenen $n$ ve $m$ için dizayn matrisi,

$\mathbf{A}=\left[\begin{array}{llllll}a_{00} & a_{10} & a_{11} & b_{11} & a_{20} & \ldots\end{array}\right]$

ve bilinmeyenler matrisi,

$\mathbf{X}=\left[\begin{array}{llllll}A_{00} & A_{10} & A_{11} & B_{11} & A_{20} & \ldots\end{array}\right]$

ile,

$\mathbf{X}=\left(\mathbf{A}^{\mathrm{T}} \mathbf{A}\right)^{-1} \mathbf{A}^{\mathrm{T}} \mathbf{l}$

modelleme parametreleri olarak $A_{n m}$ ve $B_{n m}$ katsayıları, boylam ve enlem farkları için ayrı ayrı hesaplanır. Burada $\mathbf{l}$ ölçü vektörü olarak alınır. Buradan;

$\mathbf{v}=\mathbf{A X}-\mathbf{l}$

$m_{0}= \pm \sqrt{\frac{[v v]}{n-u}}$

ile "veri-model uyuşum duyarlığı” bulunur. Burada $n$; ölçü sayısı, $u$; bilinmeyenler sayısıdır.

Yeryuvarına göre çok küçük sayılabilecek alanlarda, trigonometrik fonksiyonlar birbirine yakın değerlerde olduğundan, küresel harmonik fonksiyonlarla modellemede normal denklemler matrisi $\mathbf{N}=\left(\mathbf{A}^{\mathrm{T}} \mathbf{A}\right)$ zayıf kondüsyonlu olur ve inversinin alınması zorlaşır. Bu problem, “Genelleştirilmiş Tikhonov Düzenleme Algoritması” ile çözülebilmektedir. Algoritmaya göre; 
$\mathbf{X}=\left(\mathbf{A}^{\mathrm{T}} \mathbf{A}+\lambda^{2} \mathbf{B}^{\mathrm{T}} \mathbf{B}\right)^{-1} \mathbf{l}$

olur. Burada $\lambda$ düzenleme parametresi ve $\mathbf{B}$ boyutları bilinmeyenler sayısına bağlı bir kare matristir ve

$\mathbf{B}=\left[\begin{array}{rrr}1 & 0 & \ldots \\ -1 & 1 & \ldots \\ \ldots & \ldots & \ldots\end{array}\right]$

şeklinde alınır. Optimal çözüm için $\lambda$ parametresi değiştirilerek hesaplanan $m_{0}$ değerleri, bir $\left(\lambda, m_{0}\right)$ eğrisinde incelenir. Maksimum eğrilik noktası (L şekli) optimal çözümü veren $\lambda$ olur (Yagle, 2005).

\section{Datum Transformasyonu Uygulamaları}

\subsection{Test Verisinin Tanımı}

$\mathrm{Bu}$ çalışmada, kamu kurum ve kuruluşlarından derlenen ortak 2676 noktanın ITRF96 (2005 epoğunda) ve ED50 datumlarındaki elipsoidal boylam ve enlem değerleri esas alınmıştır (Eren \& Uzel, 2008).

Elipsoidal koordinat farkları;

- $\quad \lambda_{\text {fark }}=\lambda_{\text {ITRF } 96}-\lambda_{E D 50} \cong-1.6^{\prime \prime}(\sim 38 m)$

- $\varphi_{\text {fark }}=\varphi_{\text {ITRF96 }}-\varphi_{E D 50} \cong-3.5^{\prime \prime}(\sim 108 \mathrm{~m})$

civarındadır.

Her noktanın ED50 koordinatlarının trendleri "Standard Molodensky Transformasyonu Formülleri” kullanılarak hesaplanmıştır (NGA, 2014).

Hesaplamalarda, uluslararası kuruluşların benimsediği;

$\Delta X=-87 m ; \Delta Y=-98 m ; \Delta Z=-121 m ; \Delta a=-251 m ; \Delta f=1.419266 \times 10^{-5}$

değerleri alınmıştır. Buna göre,

$\min \Delta \lambda=-2.0891^{\prime \prime} ; \max \Delta \lambda=-0.4337^{\prime \prime}(\mathrm{DMA}, 1988 ; \mathrm{IHO}, 2008) ; \min \Delta \varphi=-3.6121^{\prime \prime} ; \max \Delta \varphi=-3.0661^{\prime \prime}$

bulunmuştur. Hesaplanan trend değerleri ED50 koordinatlarına eklenerek, Eşitlik (2)'den, $\Delta \lambda$ ve $\Delta \varphi$ farkları hesaplanmıştır. $\mathrm{Bu}$ farklar; iki elipsoid arasındaki ölçek ve öteleme etkisinden olurunca bağımsızdır ve orijinal farkların yaklaşık onda biri mertebesindedir. Bu nedenle kaba hata araştırmasına daha uygundurlar.

Kaba hatalı noktalar, deneysel olarak bir yaklaşım ile $0.0^{\prime \prime}<\Delta \lambda<1.0^{\prime \prime}$ ve $-1.0^{\prime \prime}<\Delta \varphi<0.0^{\prime \prime}$ alınarak belirlenmiş ve ayıklanmıştır. Belirlenen kaba hatalı 60 nokta çıkarıldıktan sonra, rastgele ve olurunca homojen dağılmış "kontrol noktaları seti” olarak 25 nokta seçilmiş ve veriden ayırılmıştır. Böylece kalan 2591 noktanın dağı̆lımı Şekil 1'de görülmektedir. 


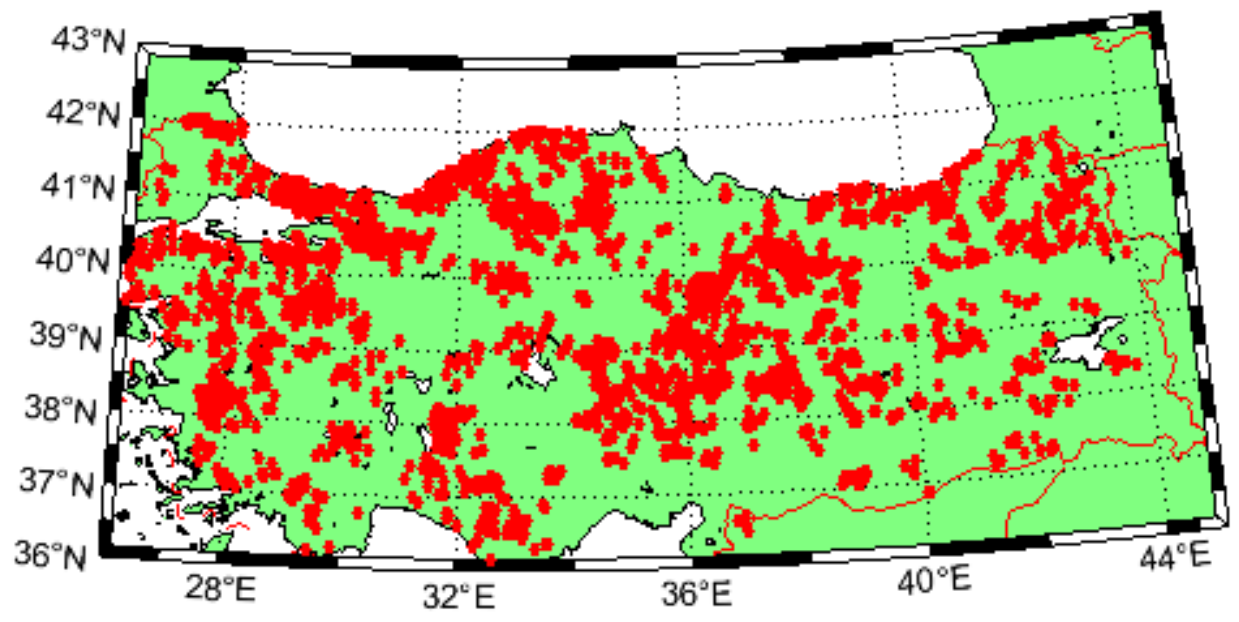

Şekil 1: Test ağı noktalarının dağııımı

Kontrol noktalarının dağılımı Şekil 2'de görülmektedir.

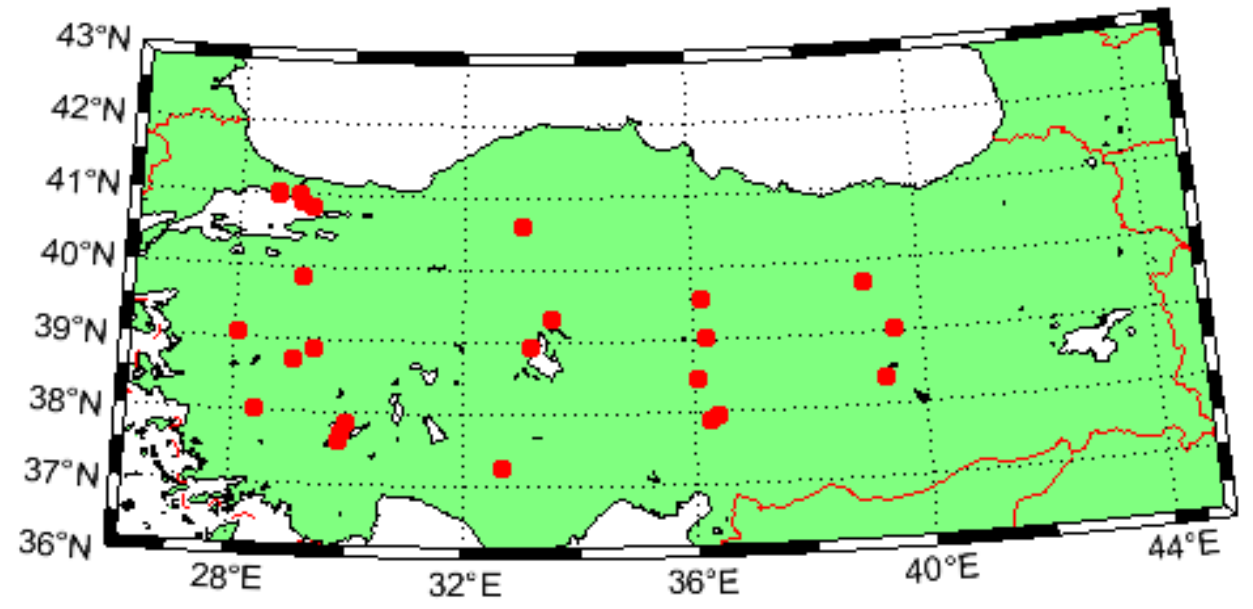

Şekil 2: Kontrol noktaları ağı

Datum transformasyonunda kullanılacak orijinal verinin istatistik özellikleri Tablo 1'de verilmektedir.

Tablo 1: Orijinal verinin $\Delta \lambda$ ve $\Delta \varphi$ farkları istatistiği

\begin{tabular}{cccc}
\hline Parametre & Minimum (") & Maksimum (") & Ortalama (") \\
\hline Boylam fark1 $(\Delta \lambda)$ & 0.005 & 0.569 & 0.269 \\
Enlem fark1 $(\Delta \varphi)$ & -0.412 & -0.003 & -0.230 \\
\hline
\end{tabular}




\subsection{Verinin Gridlenmesi: Uzunluğun Tersi Ağırlıklı Enterpolasyon}

Araştırma amaçlı olarak, boylamları $27.75^{\circ}-44.00^{\circ}$ ve enlemleri $37.00^{\circ}-41.75^{\circ}$ alanında $15^{\prime} \times 15^{\prime}$ lık grid ağı tanımlanmıştır. Böylece, $66 \times 20=1320$ noktalık bir ağ oluşturulmuştur. Bu grid ağının noktalarının boylam farkları $\mathrm{d} \lambda_{\text {grid }}$ ve enlem farkları $\mathrm{d} \varphi_{\text {grid }}$, Eşitlik (3)'e uygun olarak, uzunluğun tersi ağırlıklı enterpolasyon ile hesaplanmıştır. Enterpolasyonda, $s<1.5^{\circ}$ alınmıştır. Çünkü Marmara Denizi’ndeki ve veri yoğunluğunun az olduğu bölgeler için ancak bu uzunluk sınırlaması ile çözüm sağlanabilmiştir. Daha yoğun veri ile daha küçük $s$ değerleri de denenebilecektir.

Hesaplanan $\mathrm{d} \lambda_{\text {grid }}$ ve $\mathrm{d} \varphi_{\text {grid }}$ değerlerinin istatistiği Tablo 2'de verilmektedir.

Tablo 2: $\mathrm{d} \lambda_{\text {grid }}$ ve $\mathrm{d} \varphi_{\text {grid }}$ değerleri istatistiği

\begin{tabular}{cccc}
\hline Parametre & Minimum (") & Maksimum (") & Ortalama (") \\
\hline Boylam $\left(\mathrm{d} \lambda_{\text {grid }}\right)$ & 0.1574 & 0.3416 & 0.2689 \\
Enlem $\left(\mathrm{d} \varphi_{\text {grid }}\right)$ & -0.2930 & -0.1886 & -0.2313 \\
\hline
\end{tabular}

Tablo 1'deki orijinal verilerle Tablo 2'deki gridlenmiş veriler karşılaştırıldığında, enterpolasyon ile minimum ve maksimum değerlerinin birbirine yaklaştı̆̆ ve ortalamaların çok az değiştiği görülmektedir. Bu sonuç, uzunluğun tersi ağırlıklı enterpolasyon yönteminin güvenirliğinin ve doğruluğunun kanıtıdır.

Gridlenmiş boylam ve enlem farklarının bileşke vektörleri, Şekil 3’te görülmektedir. Bu vektörlerin, artık öteleme etkilerini, kabuk hareketlerini ve ED50'deki bozulmaları da içerdiği söylenebilir.

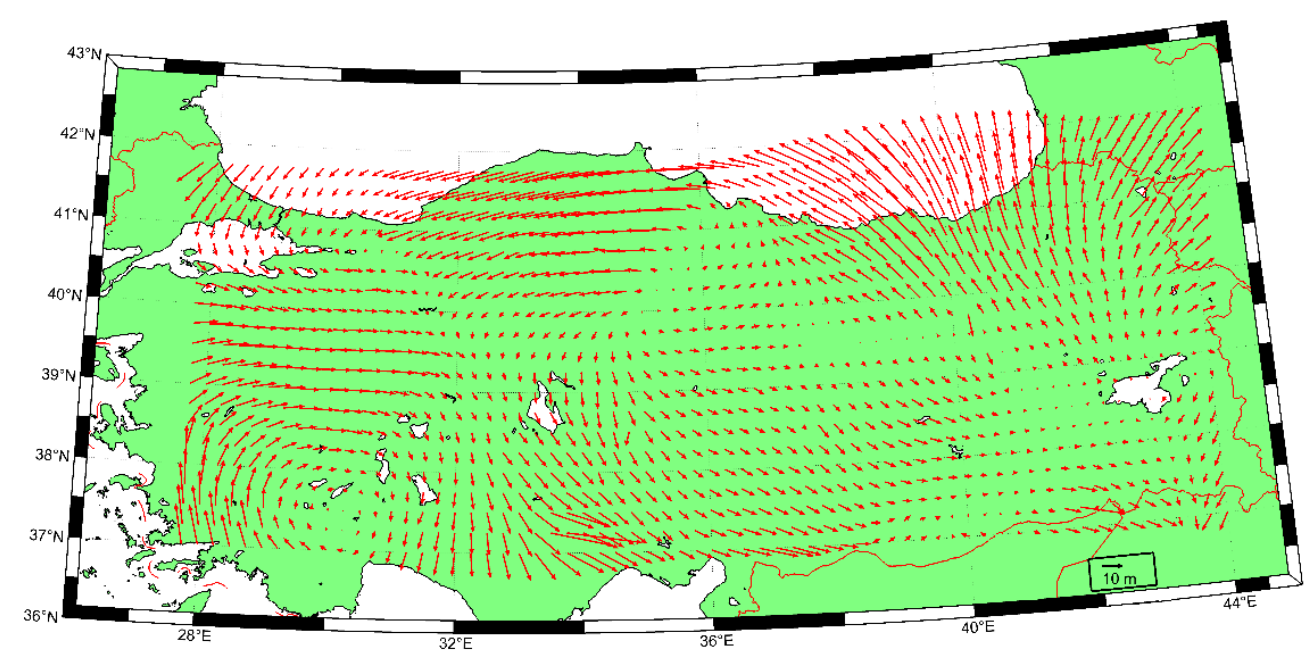

Şekil 3: Gridlenmiş boylam ve enlem farklarının bileşke vektörleri

Kontrol noktalarının $\mathrm{d} \lambda_{\text {ent }}$ ve $\mathrm{d} \varphi_{\text {ent }}$ değerleri, gridlenmiş veri kullanılarak, uzunluğun tersi ağırlıklı enterpolasyon yöntemiyle hesaplanmıştır. Bu değerlendirmede hücreler $s<0.5^{\circ}$ olarak alınmıştır. Kontrol noktalarının koordinatlarına standart Molodensky transformasyonu eşitliğinden hesaplanan $\Delta \lambda$ ve $\Delta \varphi$ değerleri ve $\mathrm{d} \lambda_{\text {ent }}$ ve $\mathrm{d} \varphi_{\text {ent }}$ değerleri eklenerek, bu noktaların ITRF96 datumundaki değerleri bulunur. Yani; 
$\lambda_{\text {ITRF 96,Hesap }}=\lambda_{E D 50}+\Delta \lambda+\Delta \lambda_{\text {ent }}$

$\varphi_{I T R F 96, \text { Hesap }}=\varphi_{E D 50}+\Delta \varphi+\Delta \varphi_{\text {ent }}$

olur. Kontrol noktalarının enlem ve boylamlarının bilinen $\left(\varphi_{\text {orijinal }}, \lambda_{\text {orijinal }}\right)$ ve hesaplanan değerleri arasındaki farklar gerçek hata olarak alınabilir ve

$\varepsilon_{\lambda}=\lambda_{\text {orijinal }}-\lambda_{\text {ITRF } 96, \text { Hesap }}$

$\varepsilon_{\varphi}=\varphi_{\text {orijinal }}-\varphi_{\text {ITRF } 96, \text { Hesap }}$

olarak hesaplanır. Buradan, kontrol noktaları için birim ağırlıklı karesel ortalama hata;

$m_{o K}= \pm \sqrt{\frac{[\varepsilon \varepsilon]}{n}}$

şeklindedir. Kontrol noktaları değerlendirme sonuçları Tablo 3 'te verilmektedir.

Tablo 3: Kontrol noktaları sonuçları istatistiği

\begin{tabular}{ccccc} 
Parametre & Minimum $(\mathbf{m})$ & Maksimum $(\mathbf{m})$ & Ortalama $(\mathbf{m})$ & Karesel Ort. Hata $(\mathbf{m})$ \\
\hline Boylam $\left(\mathrm{d} \lambda_{\text {ent }}\right)$ & -0.59 & 0.53 & -0.04 & 0.225 \\
Enlem $\left(\mathrm{d} \varphi_{\text {ent }}\right)$ & -0.20 & 0.51 & 0.07 & 0.189 \\
\hline
\end{tabular}

Tablo 3'ten, kontrol noktalarının boylam ve enlem doğrultusundaki doğruluklarından, bu yöntemi kullanarak hesaplanan bir noktanın ITRF96 datumundaki lineer nokta konum doğruluğu, ortalama \pm 0.294 m olur. Bu sonuç, şimdiye kadar, tüm Türkiye için elde edilen sonuçlar içinde en iyilerden biridir ve bu yöntemin üzerinde durulmaya değer olduğunun bir kanıtıdır (Aktuğ vd. 2011; Eren \& Uzel, 2008; Firat \& Lenk, 2002).

\subsection{Küresel Harmonik Fonksiyonlar ile Modelleme}

Eşitlik (4) ile verilen genel küresel harmonik fonksiyon; $r=1, R=6374.5 \mathrm{~km}, n=5, m=5$ için açılmıştır. Eşitlik (5) ile verilen 36 katsayı hesaplanarak, 36 bilinmeyene kadar çözüm söz konusu olmaktadır.

Değerlendirmeye 36 bilinmeyen ile başlanmış ve boylam ve enlem farkları için en uygun model parametreleri ve düzenleme parametresi $\lambda$ araştırılmıştır. $\mathbf{A}=\left[\begin{array}{llll}a_{00} & a_{10} & \cdots & b_{33}\end{array}\right]$ olarak 16 bilinmeyen ve $\lambda=1 \times 10^{-9}$ en uygun değer olarak belirlenmiştir. 2591 noktanın 16 bilinmeyen ile değerlendirmesi sonucunda;

- boylam için modelleme duyarlı̆g ${ }_{1}, \mathrm{~m}_{m \lambda}= \pm 0.0350^{\prime \prime}(\sim 0.84 \mathrm{~m})$,

- $\quad$ enlem için modelleme duyarlığ,$_{m \varphi}= \pm 0.0245^{\prime \prime}(\sim 0.76 m)$,

bulunmuştur.

Düzgünleştirilmiş ve gridlenmiş verilerle çalışıldığında, KHF'lerin performanslarının arttığı bilinmektedir (Torge, 2001). Bu 
çerçevede, gridlenmiş veri de KHF'lerle modellendirilmiştir. Bu değerlendirme sonucu;

- $\quad$ boylam için modelleme duyarlı̆̆,$_{m \lambda}= \pm 0.0177^{\prime \prime}(\sim 0.424 \mathrm{~m})$,

- $\quad$ enlem için modelleme duyarlığ,$_{m \varphi} \mathrm{m}_{m \varphi} \pm 0.0129^{\prime \prime}(\sim 0.398 \mathrm{~m})$,

bulunmuştur. Orijinal veri sonuçlarıyla karşılaştırıldığında, grid verinin KHF'lerle modellenmesi ile büyük oranda iyileşmenin olduğu görülmektedir.

Grid verinin doğruluğu kontrol noktaları ile kontrol edilmiştir. Bunun için; kontrol noktaları verisinden, kontrol noktaları dizayn matrisi, $\mathbf{A}_{\boldsymbol{K}}$;

$\mathbf{A}_{\boldsymbol{K}}=\left[\begin{array}{llll}k a_{00} & k a_{10} & \ldots & k b_{33}\end{array}\right]$

16 bilinmeyene göre oluşturulmuştur. Modellemede boylam için bilinmeyenler $\mathbf{X}_{\lambda}$ ve enlem için bilinmeyenler $\mathbf{X}_{\varphi}$ ise, modelden boylam ve enlem farkları;

$\mathrm{d} \lambda_{\text {model }}=\mathbf{A}_{\boldsymbol{K}} \mathbf{X}_{\lambda}$

$\mathrm{d} \varphi_{\text {model }}=\mathbf{A}_{\boldsymbol{K}} \mathbf{X}_{\varphi}$

olarak elde edilir. Eşitlik (14) ve Eşitlik (15)'e göre, karesel ortalama hatalar hesaplanmıştır. Sonuçlar Tablo 4'te verilmektedir.

Tablo 4: Grid verinin küresel harmonik modellemesinin doğruluğu

\begin{tabular}{ccccc}
\hline Parametre & Minimum $(\mathbf{m})$ & Maksimum (m) & Ortalama (m) & Karesel Ort. Hata (m) \\
\hline Boylam $\left(\varepsilon_{\lambda}\right)$ & -0.67 & 0.78 & -0.09 & \pm 0.38 \\
Enlem $\left(\varepsilon_{\varphi}\right)$ & -0.79 & 0.54 & 0.03 & \pm 0.28 \\
\hline
\end{tabular}

Tablo 4, Tablo 2 ile karşılaştırıldığında Tablo 2 sonuçlarının daha iyi olduğu görülmektedir. Ancak; Tablo 4 sonuçları, daha az ortak nokta sayısına karşın Aktuğ vd. (2011) değerleriyle oldukça uyumludur.

\section{Sonuçlar ve Öneriler}

Koordinat farklarıyla datum transformasyonu yaklaşımında; bir grid ağı oluşturulur veya veri modellenir. Gridleme veya modellemede kullanılacak yöntemler için sistematik bileşenlerden arındırılmış veri gerekmektedir. ITRF96 ile ED50 koordinatları arasındaki farkların yaklaşık \%90’1 trenddir. Bu trendin büyük bir kısmı "Standart Molodensky Transformasyonu" ile giderilebilir ve böylece enterpolasyon veya modelleme sürecinde trend belirleme gerekmez.

Türkiye için koordinat farkları ortalama boylamda $-1.6^{\prime \prime}$ ve enlemde $-3.5^{\prime \prime}$ iken, trend giderildikten sonra, datum transformasyonu için değerlendirilecek değerler ortalama boylamda $0.269^{\prime \prime}$ ve enlemde $-0.230^{\prime \prime}$ mertebesindedir.

Gridleme çalışmalarında, veriye uygun enterpolasyon yönteminin seçimi önemlidir. Türkiye için ITRF96 ile ED50 arasındaki 
koordinat farkları verisi, doğruluk açısından heterojen yapıdadır. Farklı derecelerde, farklı zamanlarda üretilen komşu noktalar söz konusudur. Bu nedenle, veriyi harmanlama, düzgünleştirme özelliği de olan yöntemlerden birinin seçimi uygun olacaktır. Bu çalışmada, uzunluğun tersi ağırlıklı enterpolasyon yöntemi seçilmiş ve denenmiştir.

Kamu kurumlarından derlenen ortak noktalardan 25 adedi kontrol noktas1 ve 2591 nokta transformasyon noktası olarak seçilmiştir. Tüm noktaların trendleri hesaplanmış ve bu değerler ED50 koordinatlarına eklenmiştir. Araştırma amacıyla, 15'x15' lık 66x20=1320 noktalık bir grid ağı oluşturulmuş ve bu noktaların boylam farkları d $\lambda$ ve enlem farkları d $\varphi$, uzunluğun tersi ağırlıklı enterpolasyon ile orijinal farklardan hesaplanmıştır. Gridlenmiş bu değerlerden, yine uzunluğun tersi ağırlıklı enterpolasyon ile kontrol noktalarının $\mathrm{d} \lambda$ ve $\mathrm{d} \varphi$ farkları hesaplanmıştır. Orijinal verinin istatistik özellikleri ile gridlenmiş verinin istatistik özellikleri karşılaştırıldığında, uzunluğun tersi ağırlıklı enterpolasyon yönteminin, transformasyon için kullanılabilir, tutarlı bir enterpolasyon yöntemi olduğu söylenebilir. Kontrol noktalarının gerçek ITRF96 koordinatlarıyla ve gridlenmiş veriden hesaplanan koordinatları arasındaki farklar değerlendirilerek; doğruluklar, boylamda $\pm 0.225 \mathrm{~m}$ ve enlemde $\pm 0.189 \mathrm{~m}$ bulunmuştur. Bu sonuçlar, oldukça umut vericidir.

Orijinal veri KHF'lerle modellenmiştir. $n=3$ ve $m=3$ 'e kadar açılımın yeterli olduğu ve 16 bilinmeyen ile modellemenin yapılabileceği belirlenmiştir. Bu modellemenin duyarlığı; boylamda $\pm 0.035^{\prime \prime}(\sim 0.84 \mathrm{~m})$ ve enlemde $\pm 0.0245^{\prime \prime}(\sim 0.76 \mathrm{~m})$ bulunmuştur. Gridlenmiş veri de KHF'lerle modellenmiştir. Bu modellemenin duyarlığı; boylamda $\pm 0.177^{\prime \prime}(\sim 0.424 \mathrm{~m})$ ve enlemde $\pm 0.0129 "$ " ( 0.398 m) bulunmuştur. Bu sonuçlar, orijinal verinin modellenmesinden elde edilen doğrulukların yaklaşık iki katıdır. Grid verinin küresel harmonik modelinin doğruluğu da kontrol noktaları ile kontrol edilmiştir. Sonuçlar, boylamda $\pm 0.38 \mathrm{~m}$ ve enlemde, \pm 0.28 m’dir. Gridleme ve modellemenin doğrulukları yöntemler üzerinde çalışmak için cesaret vericidir. CORS TR Projesi’nin bitiminden sonra, çok sayıda ortak noktanın üretilmiş olduğu varsayılabilir. Bu nedenle, daha yoğun verilerle ve farklı kontrol noktaları ile çalışmalar sürdürülmelidir. Radyal esaslı diğer enterpolasyon yöntemleri, en uygun hücre boyutları, araştırma konularından bazılarıdır. Grid ağı ve modeller; yerel datum parametrelerinin birleştirilmesi için temel altyapıyı oluşturabilirler. Yerel parametrelerin birleştirilmesi ve datum transformasyonunda sürekliliğin sağlanması jeodezinin güncel görevi olacaktır.

\section{Teşekkür}

Bu çalışmadaki tüm değerlendirmeler, MATLAB'da kodlanan yazılımlar ile gerçekleştirilmiştir (URL-2, URL-3). Tüm haritalar MATLAB ortamında Pawlowicz (2020)'nin M_Map paketi kullanılarak çizdirilmiştir.

\section{Yazar Katkısı}

İlke Deniz: Fikir, Literatür taraması, Veri işleme, Analiz ve yorumlama, Yazım. Şenol Hakan Kutoğlu: Tasarım, Denetleme, Makale değerlendirme. Rasim Deniz: Veri toplama, Makale değerlendirme.

\section{Çıkar Çatışması Beyanı}

Yazarlar, bu çalışmada bilinen ilgili herhangi bir finansal veya finansal olmayan çıkar çatışması olmadığını beyan ederler. 


\section{Kaynaklar}

Aktuğ, B., Seymen, S., Kurt, M., Parmaksız, E., Lenk, O., Sezer, S. \& Özdemir, S. (2011). ED-50 (European Datum-1950) ile TUREF (Türkiye Ulusal Referans Çerçevesi) Arasında Datum Dönüşümü. Harita Dergisi, 146, 8-17.

Anjyo, K., Lewis, J. P., \& Pighin, F. (2014). Scattered data interpolation for computer graphics. In ACM SIGGRAPH 2014 Courses (ss. 169).

Çepni, M. S., \& Deniz, R. (2005). Sonlu Elemanlar Yönteminin Dönüşümlerde Kullanılması. Jeodezi ve Jeoinformasyon Dergisi, (93), 2029.

Deniz, İ. (2020). Investigation of Height-Dependent Systematic Component of ZTDs Using Spherical Harmonic Functions (SHF) and Empirical Orthogonal Functions (EOF). Proceedings of the FIG Working Week 2020, Amsterdam, Hollanda.

DMA. (1998). Defence Mapping Agency Technical Reports, Washington, ABD.

Eren, K., \& Uzel, T. (2008). CORS-TR Datum Dönüşümü Raporu, Ulusal CORS sisteminin kurulması ve datum dönüşümü projesi. İstanbul Kültür Üniversitesi.

Fırat, O., \& Lenk, O. (2002). Avrupa Datumu 1950 (ED -50) ile Türkiye Temel GPS Ağı 1999 (TUTGA-99) arasında Datum Dönüşümü. TUJK 2002 Yılı Bilimsel Toplantısı Tektonik ve Jeodezik Ağlar Çalıştayı, İznik, Bursa.

HKMO (2005). Açıklamalı-Örneklemeli Büyük Ölçekli Harita ve Harita Bilgileri Üretim Yönetmeliği, Ankara.

HKMO (2018). Açıklamal1-Örneklemeli Büyük Ölçekli Harita ve Harita Bilgileri Üretim Yönetmeliği, Ankara.

IHO. (2008). User's Handbook on Datum Transformations Involving WGS 84. USA: International Hydrographic Bureau (IHO).

Kutoğlu, H., \& Ayan, T. (1998). WGS84'den ED50 Koordinat Sistemine Dönüşümde Yükseklik Sorunu İçin Yeni Bir Yaklaşım. Harita ve Kadastro Mühendisliği Dergisi, 85, 82-90.

Kutoglu, H. S., Mekik, C., \& Akcin, H. (2003). Effects of errors in coordinates on transformation parameters. Journal of surveying engineering, 129(3), 91-94.

Leick, A. (2004). GPS satellite surveying. $3^{\text {rd }}$ edition. New Jersey: Wiley.

Mitas, L., \& Mitasova, H. (1999). Spatial interpolation. Geographical information systems: principles, techniques, management and applications, $1(2)$.

NGA. (2014). WGS 84 Definition and Relationships with Local Geodetic Systems, NGA Standardization Document, Department of Defense, World Geodetic System 1984, Office of Geomatics, USA.

Pawlowicz, R. (2000). M_Map: a mapping package for Matlab. University of British Columbia Earth and Ocean Sciences.

Torge, W. (2001). Geodesy. Berlin: Walter de Gruyter.

Vanicek, P., \& Krakiwski, E. I. (1986). Geodesy: The Concepts. Amsterdam: Elsevier.

Yagle, A. E. (2005). Regularized matrix computations. matrix, 500, 10.

URL-1: https://pro.arcgis.com/en/pro-app/help/analysis/geostatistical-analyst/how-inverse-distance-weighted-interpolation-works.htm (Erişim Tarihi: Temmuz 2020).

URL-2: https://www.mathworks.com/matlabcentral/answers/17775-gridding-and-interpolate-data?s_tid=srchtitle (Erişim Tarihi:

Temmuz 2020).

URL-3: http://github.com/OSGeo/PROJ/pull/1897 (Erişim Tarihi: Temmuz 2020). 